\title{
Is urethral microscopy useful in symptomatic male patients without urethral discharge?
}

\author{
Borg $\mathrm{S}^{1}$, Daniel J1, Forsyth $\mathrm{S}^{1}$ \\ 1. Sexual Health Department, The Great Western Hospital \\ Hoine life!
}

\section{Introduction}

National guidelines recommend male patients symptomatic of urethritis or epididymo-orchitis undergo urethral swab for microscopy.

The aim is to identify Neisseria gonorrhoea (GC) or non-gonococcal urethritis (NGU) so they can be treated the same day $(I, 2)$.

Urethral swabs and microscopy require time, resources, trained healthcare workers, and can be uncomfortable (3). If symptoms could be accurately associated with microscopy findings, then resources could be saved and patient discomfort minimised, without increased risk of missing an early diagnosis of GC or NGU.

We noticed that symptomatic patients without urethral discharge often had negative microscopy findings.

Our aim is to determine the proportion of symptomatic male patients without urethral discharge who have positive findings on urethral swab microscopy, and explore associations between presenting symptoms and microscopy findings.

\section{Methods}

A retrospective audit on 182 consecutive male patients who attended our clinic over a seven-month period in 2017.

Inclusion criteria were symptomatic male patients who underwent microscopy.

Patients were grouped as:

I) urethral discharge (UD-present), and

2) no urethral discharge but other symptoms (UD-absent; further subdivided into:
x) dysuria,
y) urethral discomfort or penile irritation, or
z) testicular pain or discomfort).

Microscopy outcomes were cross-tabulated against presenting symptoms.. A chi-squared test was used to determine statistical significance.

In the UD-absent subgroup, multivariate logistic regression determined if age, dysuria, urethral discomfort or penile irritation, or testicular pain or discomfort influenced the microscopy outcome.

\section{Results}

One-hundred and eighty patients (99\%) met the inclusion criteria; 75 were UD-present, and I05 UD-absent.

Graph I: Proportion of patients with positive findings (NGU or GC) on microscopy

Patients with urethral discharge

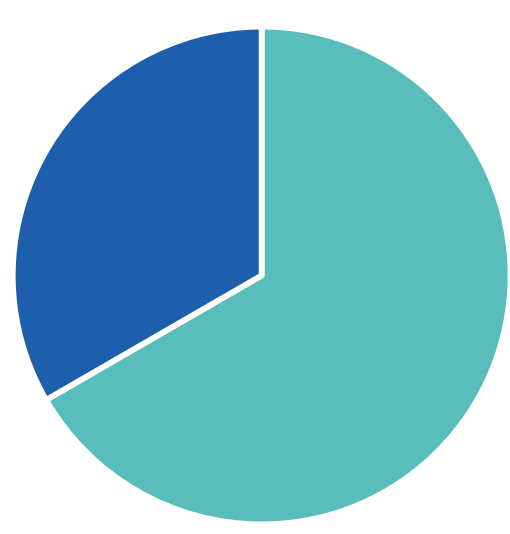

+ findings on microscopy $(\mathrm{n}=50) \quad+$ + findings on miroscopy $(\mathrm{n}=34)$

- findings on microscopy $(n=25) \quad$ - findings on microscopy $(n=7 \mathrm{I})$

(Difference between \% of patients with + microscopy findings $p<0.001$ )

There was no significant association between positive findings on microscopy and having only one of dysuria, urethral discomfort/penile irritation, or testicular pain or discomfort; having two of the symptom groups; or having all three $(p>0.05)$.

There was a significant association between the presence of dysuria and positive microscopy findings, but not age, urethral discomfort or penile irritation, or testicular pain or discomfort (Table I).

\begin{tabular}{|l|c|c|c|}
\hline \multicolumn{4}{|c|}{ Table 2: Predictors of positive microscopy } \\
\hline & Odds ratio & $95 \% \mathrm{Cl}$ & P-value \\
\hline Age & 0.96 & $0.9-.10$ & 0.08 \\
\hline Dysuria & 4.73 & $1.6-14.1$ & $<0.01$ \\
\hline $\begin{array}{l}\text { Urethral discomfort or } \\
\text { penile irritation }\end{array}$ & 2.33 & $0.8-6.8$ & 0.12 \\
\hline $\begin{array}{l}\text { Testicular pain or } \\
\text { discomfort }\end{array}$ & 2.09 & $0.8-5.8$ & 0.16 \\
\hline
\end{tabular}

Intercept $0.36,95 \% \mathrm{Cl}: 0.07-1.79$

\section{Conclusion}

\section{There was a significant difference between the percentage of symptomatic patients with positive findings on microscopy in} those with and without urethral discharge (67\% vs $33 \%)$.

\section{In a patient presenting with symptoms other than urethral discharge, the likelihood that positive findings on microscopy} would occur in a patient with dysuria was 4.7 times more likely than if they didn't have dysuria.

Knowing which symptoms are more likely to indicate urethritis will allow more accurate triage of which patients are unsuitable for online screening and which to treat symptomatically if microscopy is not available.

In situations with limited resources, patients without urethral discharge presenting with dysuria could be prioritised. However, further research is required to identify and stratify which patients require microscopy. 